ORIGINAL ARTICLE

\title{
Herbal creams used for atopic eczema in Birmingham, UK illegally contain potent corticosteroids
}

\author{
H M Ramsay, W Goddard, S Gill, C Moss
}

See end of article for authors' affiliations

........................

Correspondence to: Dr H M Ramsay, Consultant Dermatologist and Honorary Senior

Clinical Lecturer,

Department of

Dermatology, Royal

Hallamshire Hospital,

Glossop Road, Sheffield

S10 2JF, UK;

Helen.Ramsay@sth.nhs.uk

Accepted 10 April 2003
Aims: To determine whether "herbal creams" reported as being effective for the treatment of childhood atopic eczema contained corticosteroids.

Methods: Patients attending the paediatric dermatology clinic at Birmingham Children's Hospital, April 2001 to March 2002, and who reported using "herbal creams" with good effect for atopic eczema were asked to submit the cream for analysis. Hydrocortisone, clobetasone butyrate, betamethasone valerate, and clobetasol propionate were analysed by HPLC.

Results: Twenty four creams from 19 patients, median (interquartile range) age 3.82 (0.69-7.98) years were analysed. All five creams labelled Wau Wa and the two labelled Muiijiza cream contained clobetasol propionate. Thirteen of 17 unnamed creams contained corticosteroids: clobetasol proprionate $(n=4)$, clobetasol proprionate + hydrocortisone $(n=1)$, betamethasone valerate $(n=2)$, clobetasone butyrate $(n=3)$, and hydrocortisone $(n=2)$; there was an unidentified peak in one. Further analysis suggested Wau Wa cream contained approximately $20 \%$ proprietary Dermovate Cream in a paraffin base. No parents were aware that the creams contained steroid.

Conclusions: The majority of herbal creams analysed illegally contained potent or very potent topical steroids. There is an urgent need for tighter regulation of herbal creams and for increased public education about the potential dangers of alternative therapies.
A topic eczema is an increasingly common disease of childhood associated with inflammation, itching, pain, and a tendency to superficial infection. Conventional treatments are often messy, time consuming, and distressing to both parents and child. Many parents are worried about using topical steroids on their children because of the fear of side effects, and seek alternative, natural remedies including herbal products.

There have been previous reports of Chinese herbal creams illegally containing steroids, ${ }^{1-6}$ the most recent being a series from London in 1999 that identified potent corticosteroids in 8 of 11 creams. $^{1}$ Despite this, we continue to see patients in our paediatric eczema clinic who report dramatic responses to "herbal creams". The creams are usually of Indian/Pakistani origin, reflecting the demographics of our population. The aim of this study was to determine whether any of these creams being used by children in Birmingham illegally contained steroids.

\section{METHODS}

Nineteen patients, median (interquartile range) age 3.82 $(0.69-7.98)$ years attending the paediatric dermatology clinic at Birmingham Children's Hospital between March 2001 and April 2002 who reported using "herbal creams" with good effect for atopic eczema submitted samples of the creams for corticosteroid analysis using high pressure liquid chromatography (HPLC). The department saw a total of 451 new patients with atopic eczema during this period.

\section{RESULTS}

Twenty four "herbal creams" were received. All parents believed the creams were herbal, free from steroids, and safe for use on their children. Many cost upwards of $£ 25$ and their use was often only reported only when the parents could no longer afford to continue the supply, resulting in deterioration of their child's eczema.
Seventeen were unlabelled or unnamed, five creams were labelled "Wau Wa Cream-herbal cream for the treatment of eczema", and two were labelled "Muijiza cream-contains extract of Wau Wa root". One cream was Chinese. Labelling on Wau Wa cream instructed patients to use the cream "all over" in conjunction with "Alata Soap".

All samples of Wau Wa cream and Muijiza Cream contained the very potent synthetic corticosteroid, clobetasol propionate. Thirteen $(76.5 \%)$ of the 17 unlabelled or unnamed herbal creams contained corticosteroids (table 1). Further analysis showed that Wau Wa also contained chlorocresol, which is the preservative found in Dermovate Cream (clobetasol propionate $0.0525 \%$, GlaxoSmithKline), the only proprietary brand of clobetasol available on prescription in the UK. The relative quantities of chlorocresol and clobetasol in Wau Wa suggested it comprised approximately $20 \%$ Dermovate Cream in a paraffin base. Analysis of one sample of Alata soap showed the possible presence of small quantities of hydrocortisone.

Reported sources of the creams included Indian/Pakistani herbalists or clinics in Birmingham, Leicester, and London, mail order (including one London based company who returned the cheque when a second sample was requested), a market stall in East Birmingham, and family or friends overseas (Pakistan and Tanzania). Several patients were unable or unwilling to provide details of their supplier. The one Chinese cream in this series was purchased from a Chinese herbalist in Birmingham city centre that was already under investigation by the Medicines Control Agency.

\section{DISCUSSION}

Topical corticosteroids are important in the management of childhood eczema and when used appropriately, are safe. However, the improper use of potent or very potent topical steroids can cause irreversible skin atrophy (especially on the face), spread of infection, rebound worsening of eczema on withdrawal, growth retardation, and suppression of 
Table 1 Corticosteroid content of $24^{*}$ herbal creams used by children with atopic eczema at Birmingham Children's Hospital, March 2001 to April 2002

\begin{tabular}{llc}
\hline Corticosteroid & Potency & $\mathbf{n}^{*}(\%)$ \\
\hline Negative & - & $4(16.7)$ \\
Hydrocortisone & Mild & $2(8.3)$ \\
Clobetasone butyrate & Moderate & $3(12.5)$ \\
Betamethasone valerate & Potent & $2(8.3)$ \\
Clobetasol propionate & Very potent & $11^{*}(45.8)$ \\
Clobetasol butyrate and & Very potent and mild & $1(4.2)$ \\
hydrocortisone & & $1(4.2)$ \\
Unidentified peak & - & \\
\hline
\end{tabular}

*Includes five samples labelled Wau Wa Cream, two samples labelled Muijiza Cream, and one Chinese cream.

the hypothalamic-pituitary-adrenal axis, particularly in children. ${ }^{78}$

This study has shown that, unbeknown to parents, the majority of effective "herbal creams" of Indian/Pakistani origin used by children attending the paediatric eczema clinic at Birmingham Children's Hospital illegally contain corticosteroids. There have been previous reports warning that Wau Wa contains the synthetic steroid clobetasol propionate. ${ }^{9}$ We have now identified the preservative chlorocresol in Wau Wa cream in amounts directly proportional to those found in Dermovate Cream, suggesting that this is, in all probability, the source of clobetasol in Wau Wa cream. Dermovate is rarely, if ever, prescribed to children with atopic eczema, so it is unlikely that this represents accidental contamination (for example, from the hands of a carer dipped into the pot of cream). Furthermore, quantities in excess of those to be expected by accidental contamination were identified. Thus, deliberate addition of Dermovate remains the only plausible explanation. In contrast, the small quantity of the class I steroid, hydrocortisone, found in Alata soap is unlikely to have clinical significance and may be a contaminant.

The instructions to use Wau Wa cream "all over" are particularly worrying. The median age of the children in this study was 3.82 years. If Wau Wa cream is applied using the "finger tip unit" method for topical steroid application in children, an average 3 year old would need $112 \mathrm{~g} / \mathrm{wk}$ for twice daily total body treatment, and an average 4 year old $134.75 \mathrm{~g} / \mathrm{wk}^{12}$ This is equivalent to $22.4 \mathrm{~g} / \mathrm{wk}$ of Dermovate for a 3 year old and $26.95 \mathrm{~g} / \mathrm{wk}$ for a 4 year old. Recommended doses of very potent steroids in adults are less than $50 \mathrm{~g} / \mathrm{wk}^{11}$ and even at these doses, adrenal suppression has been reported. ${ }^{11}{ }^{14-16}$
We continue to find examples of illegal herbal creams being used by our patients and have even witnessed recommendations being made in our hospital waiting room. There is an urgent need for tighter regulation and improved legislative mechanisms relating to the herbal and ethnic medicines industries and for increased public education about the potential dangers of alternative therapies. Until then, a high level of suspicion is needed regarding herbal creams that produce "miracle results".

\section{Authors' affiliations}

H M Ramsay, S Gill, C Moss, Department of Dermatology, Birmingham Children's Hospital, Steelhouse Lane, Birmingham B4 6NH, UK

W Goddard, West Midlands Quality Control Laboratory, City Hospital, Birmingham B18 7QH, UK

\section{REFERENCES}

1 Keane FM Munn SE, du Vivier AWP et al. Analysis of Chinese herbal creams prescribed for dermatological conditions. BMJ 1999;318:563-4.

2 Ernst $\mathrm{E}$. Adverse effects of herbal drugs in dermatology. $\mathrm{Br} J$ Dermatol 2000;143:923-9.

3 Wood B, Wishart J. Potent topical steroid in a Chinese herbal cream. NZ Med 1997; 1 10:420-1.

4 Allen BR, Parkinson R. Chinese herbs for eczema. Lancet 1990;336:177.

5 O'Driscoll J, Burden AD, Kingston T. Potent topical steroid obtained from a Chinese herbalist. Br J Dermatol 1992;127:543-4.

6 Graham-Brown RAC, Bourke JF, Bumphrey G. Chinese herbal remedies may contain steroids. BMJ 1994;308:473

7 Turpeinen M. Adrenocortical response to adrenocorticotrophic hormone in relation to duration of topical therapy and percutaneous absorption of hydrocortisone in children with dermatitis. Eur J Paediatr 1989;148:729-31.

8 Borzvkowski M, Grant DB, Wells RS. Cushing's syndrome induced by topical steroids used for the treatment of non-bullous ichthyosiform erythroderma. Clin Exp Dermatol 1976:1:337-42

9 Anon. Wau Wa cream. Med Digest 2001;212:2.

10 Daniels J, Shaw D, Atherton D. Use of Wau Wa in dermatitis patients. Lancet 2002;360:1025.

11 Griffiths WAD, Wilkinson JD. Topical therapy. In: Champion RH, Burton JL, Burns DA, Breathnach SM, eds. Textbook of dermatology, 6th edn. Vol. 4. Oxford: Blackwell Scientific Publications, 1998:3550-1.

12 Long CC, Mills CM, Finlay AY. A practical guide to topical therapy in children. Br J Dermatol 1998;138:293-6.

13 Katz HI, Hien NT, Prawer SE, et al. Superpotent topical steroid treatment of psoriasis vulgaris-clinical efficacy and adrenal function. J Am Acad Dermatol 1987:4:804-11.

14 Walsh P, Aeling JL, Huff L, et al. Hypothalamus-pituitary-adrenal axis suppression by superpotent topical steroids. J Am Acad Dermatol 1993;3:501-3.

15 Weston WL, Fennessey PV, Morelli J, et al. Comparison of hypothalamuspituitary-adrenal axis suppression from superpotent topical steroids by standard endocrine function testing and gas chromatographic mass spectrometry. J Invest Dermatol 1988;90:532-5

16 Ohman EM, Rogers S, Meenan FO, et al. Adrenal suppression following lowdose topical clobetasol propionate. J R Soc Med 1987;80:422-4. 